\title{
Assessing the Crown Closure of Nypa on UAV Images using Mean-Shift Segmentation Algorithm
}

\author{
Robert Parulian Silalahi ${ }^{1}$, I Nengah Surati Jaya ${ }^{2}$, Tatang Tiryana ${ }^{3}$, Fairus Mulia ${ }^{4}$ \\ ${ }^{1}$ Bogor Agricultural University, Campus IPB Dramaga, Bogor, Indonesia \\ ${ }^{2,3}$ Department of Forest Management, Faculty of Forestry, Bogor Agricultural University, Campus IPB Dramaga,
} Bogor, Indonesia

\section{Article Info}

Article history:

Received Sep 19, 2017

Revised Dec 30, 2017

Accepted Jan 17, 2018

\section{Keywords:}

Nypa

Unmanned aerial vehicles

(UAV)

Mean-shift

Segmentation

\begin{abstract}
Utilization of very high-resolution images becomes a new trend in forest management, particularly in the detection and identification of forest stand variables. This paper describes the use of mean-shift segmentation algorithm on unmanned aerial vehicles (UAV) images to measure crown closure of nypa (Nypa fruticans) and gap. The 27 combinations of the parameter values such as spatial radius (hs), range radius (hr), and minimum region size (M). Gap detection and nypa crown closure measurements were performed using a hybrid between pixel-based (maximum likelihood classifier) and objectbased approaches (segmentation). For evaluation of the approach performance, the accuracy assessment was done by comparing object-based classification results (segmentation) and visual interpretation (ground check). The study found that the best combination of segmentation parameter was the combination of hs $10, \mathrm{hr} 10$ and M 50, with the overall accuracy of 76,6\% and kappa accuracy of $55.7 \%$.
\end{abstract}

Copyright ()$^{2} 2018$ Institute of Advanced Engineering and Science. All rights reserved.

\section{Corresponding Author:}

Robert Parulian Silalahi,

Bogor Agricultural University, Campus IPB Dramaga,

Bogor, Indonesia 16680

Email: ins-jaya@apps.ipb.ac.id

\section{INTRODUCTION}

Indonesia is one of the tropical countries having a wide variety of ecosystems, starting from coastal forest/lowland (mangrove, swamp forest, peat swamp forest), dry-low land forest, up to mountainous forests, sub-alpine and alpine). To obtain a sound basis forest management planning, there is a need to provide accurate and timely supporting data related to ecosystem type, forest classes, forest density, biodiversity, standing stock, etc. One of the unique ecosystem types, which economically, ecologically, socially and culturally plays an important role is the mangrove ecosystem. In Indonesia, this mangrove ecosystem is a highly vulnerable ecosystem to conversion. One of the vegetation that goes into an association of mangrove ecosystem is nypa (Nypa fruticans). Nypa vegetation is common in estuary areas affected by tide [1]. In Indonesia, the information on the dynamic growth, status and potential of nypa has not been much studied, since the nypa ecosystem is less attractive and even frequently considered as wasteland. Some researchers indicate that nypa vegetation can provide potential economic value, either at small-scale or large-scale business. Nypa is one type of vegetation that may provide daily need product for household consumption. Several of nypa research found that nypa has a potential to be a source of food because of its have high carbohydrate and protein [2], even according to the study [3], nypa contains an ethanol to produce fuel energy.

Currently, the use of remote sensing technology in natural resource management is a must, and even for a small scale forest management. Now, there is a trend of using very high-resolution images for detailed forest management up to the tree-level forest management. Since the launch of natural resources satellites for 
civilian use in the 1970s, the development of remote sensing technology has grown rapidly, starting from a low, moderate to very high resolutions. In line with their development, the remote sensing has been also widely used for supporting either regional level, national level or individual tree level forest inventory. Today, the advent of the high and very high resolution had provided a good opportunity as well as a challenge all at once. The higher the spatial resolution, the more detailed information could be derived, the more complex and reliable approaches are required.

In a very high-resolution imagery, the use of ordinary pixel-based approach such as supervised and unsupervised classifier is often provided less accurate information, since the classification is solely alone based upon the brightness values (reflectance) of the object. The advent of object-based classification technique often called the object-based image analysis (OBIA), which consider not only the brightness values of the object but also the spatial aspect of the object being analyzed has offered a promising solution to overcome the drawback of the existing pixel-based analysis. The object-based processing is considered to have a better performance in processing high-resolution digital image because, in addition to considering the value of the pixel itself, it also considers the size (area) and shape of the object within the image.

In the last few decades, the spatial resolution of images has been improved rapidly. In addition to satellite imagery, one of the imaging platforms that produce very high-resolution images is UAV (Unmanned Aerial Vehicle). The UAV is also called to as drone (dynamic remotely operated navigation equipment). Now camera technology used in the UAV is mainly conventional camera that may provide spatial resolution up to $5 \mathrm{~cm}$. However, its recording platform is very perspective because it can be flown under the cloudy weather (fly below the cloud), unmanned, low cost, fast and relatively low risk. Thus, the UAV technology becomes a good alternative because the data obtained would be very detail and real time, as well as could be obtained easily with cheaper price. The utilization of UAV technology has been widely used to in many aspects such as mapping activity [4], quantifying spatial gap pattern [5], change detection [6], forest inventory activities [7], canopy spectral mapping [8], measuring stand variables such as crown diameter, canopy percentage and number of trees $[9,10]$ as well as estimation of the standing stock and site index quality of teak sites [11].

The Increasing resolution of the digital images from low resolution to very high resolution have encouraged a development of image processing. The current image processing trends are the use of objectbased classification methods, as a complimentary of the pixel-based approach. A pixel-based approach can be used as long as a pixel is the same size as a particular object [12]. An object-based approach is now a popular approach in high and very high-resolution image processing.

Basically, the object-classification method consists of two parts namely segmentation and classification. Conventionally, the segmentation is the initial process of an object-based classifier, then followed by classification. Image segmentation is generally defined as a process of dividing an image into groups which are spatially or spectrally uniform [13]. Object-based approaches have been applied in some works such as classification of agricultural land using SPOT-5 [14], exploration of the urban information in Cianjur [15], mapping of coral reef habitat [16], mapping land covers changes changes in mangrove ecosystems [17], detecting of forests changes caused by hurricanes [18], the object-based classification of land use in Ontario, Canada had also be examined by [19].

In this study, the authors focused on examining the appropriate object-based classification parameters for analyzing the nypa crown closure dan gap. This study integrated the pixel-based approach with maximum likelihood classifier and the mean-shift algorithm in segmentation method. The use of the mean-shift segmentation algorithm is widely used in earlier studies for benthic mapping [20], environmental management monitoring [21], land cover classification [22], change detection in SAR image [23], medical diagnosis [24]. Although the mean-shift algorithm had been succesfully examined in classifying building objects in suburban area [25], the application in classifying nypa vegetation is still challenging. Up to now, very high-resolution image utilization research for nypa ecosystem assessment is still very rare. The main objective of the study is to develop a classification technique for assessing the nypa crown closures and their gap by combining the mean-shift segmentation algorithm and maximum likelihood classifier of the pixelbased classification.

\section{RESEARCH METHOD}

\subsection{Site description}

The research was conducted within the concession area of IUPHHK PT Kandelia Alam, geographically located between $109^{\circ} 34^{\prime} 10,82^{\prime \prime}$ E \& $109^{\circ} 41^{\prime} 14,85^{\prime \prime} \mathrm{E}$; and between $0^{\circ} 35^{\prime} 18,21^{\prime \prime} \mathrm{S}$ \& $0^{\circ} 39^{\prime} 53,45^{\prime \prime}$ S. Administratively, the study site is located within Kubu Raya Regency, West Kalimantan Province (Figure 1). Field observation and field measurements were conducted in 2016, especially in areas covered by UAV (Unmanned Aerial Vehicle) imagery. 


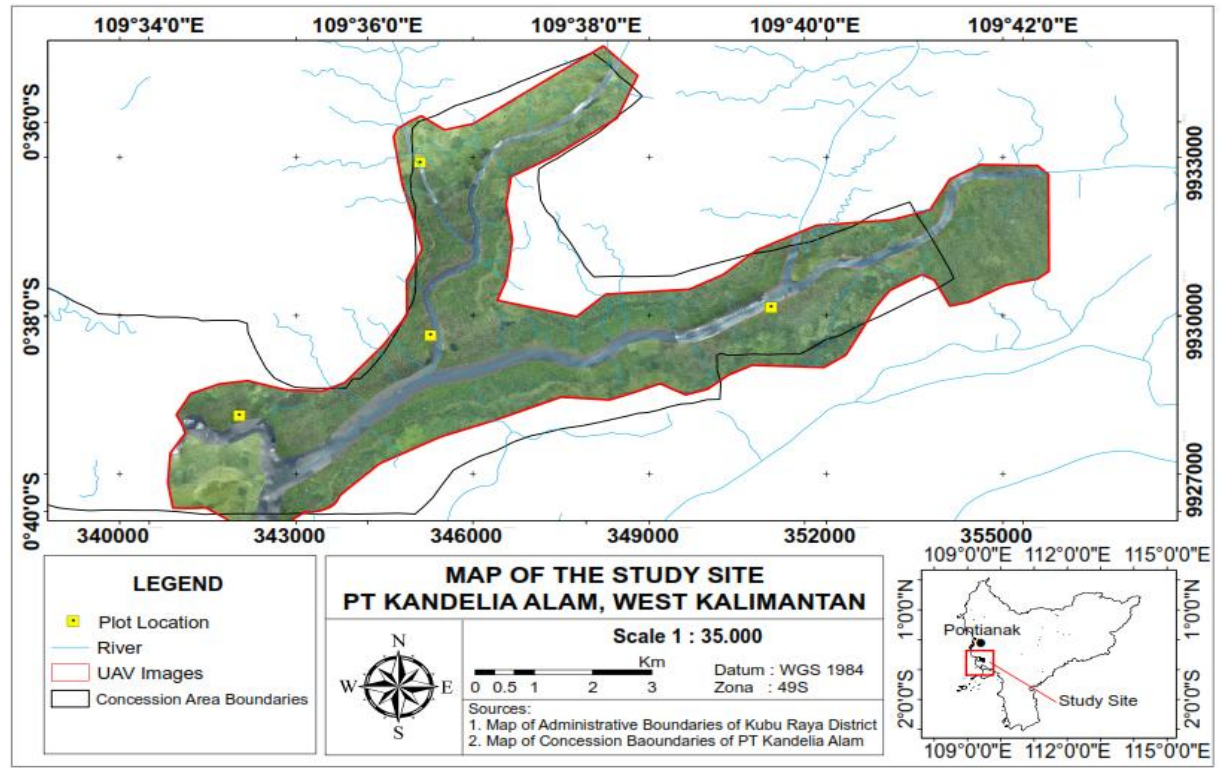

Figure 1. Study site map

\subsection{Data and Software}

The main data used in this study is a UAV image having $10 \mathrm{~cm}$ spatial resolution, 8 bits radiometric value, 4 bands, namely Red, Green, Blue, and Alpha. The preprocessing work such as rectification, radiometric correction, and geometric correction was done by data supplier. The used UAV images which cover approximately 4087 ha, were recorded in February 2016. Other supporting data used in this study are the data collected from ground measurements such as an individual diameter of nypa, length and diameter of leaves, a number of leaves, a number of stump and weight of sample nypa (100-200 gram). The processing and data analysis were done using some software such as QGIS 2.18, Orfeo Toolbox / Monteverdi 1.24, ERDAS Imagine 9.1 and Microsoft Excel 2010.

\subsection{Field Measurement and Data Processing \\ 2.3.1 Field measurement}

For comparison and accuracy assessment purposes as well as to obtain quantitative and qualitative information about the actual condition of vegetation in the field, then ground observation and measurement were performed. These field observations and measurements were conducted on four cluster plots having a size of $60 \mathrm{~m} \times 100 \mathrm{~m}$. Each cluster was divided into $15 \mathrm{sub}$ clusters (cluster elements), having a size of $20 \mathrm{~m}$ x $20 \mathrm{~m}$ each. The position of the cluster was made in such a way so that its position relatively perpendicular to the river flow.

\subsubsection{Pre-processing}

Preprocessing of UAVs includes image cropping that fit the selected cluster locations. Cropping was done to facilitate the process of segmentation and classification. The size of the UAV image for each area of interest is $1100 \times 1100$ pixels or approximately $110 \times 110$ meters in size. The area of interest was selected to cover three classes namely mangrove, nypa and gap. Each cropping process of the area of interest (AOI) image was carried out by firstly removing the alpha band, so that the image only has a Red band, Green band, and Blue band.

\subsubsection{Segmentation}

Segmentation process is the initial step in object-based image classification (OBIA), where its classification algorithm was done by merging smaller segments into larger objects based on its homogeneity (i.e., a similarity of spectral value and spatial characteristics) of the image. The segmentation method used in this research is using a mean-shift algorithm of Orfeo Toolbox/Monteverdi 1.24. In this study, the segmentation approach used was based on spectral and spatial approaches. The mean-shift algorithm was first introduced by [26] and has been proven that this method is a versatile, non-parametric method for estimating gradients in the clustering process. Some research successfully implemented the method for 
solving problems at low-level vision [27]. The parameters used in segmentation process using mean-shift algorithm are the spatial radius, range radius, and minimum region size. In this study, the authors examined 27 combinations of segmentation parameters to obtain segmentation information on canopy and gap of nypa vegetation at research location (Table 1).

Table 1. Combination of the parameter examined on the segmentation

\begin{tabular}{|c|c|c|c|c|c|c|c|c|c|c|c|}
\hline No & Setting & $\mathrm{hr}$ & hs & M & Combination & No & Setting & $\mathrm{hr}$ & hs & M & Combination \\
\hline 1 & Setting 01 & 5 & 10 & 50 & $5-10-50$ & 15 & Setting 15 & 10 & 20 & 150 & $10-20-150$ \\
\hline 2 & Setting 02 & 5 & 10 & 100 & $5-10-100$ & 16 & Setting 16 & 10 & 30 & 50 & $10-30-50$ \\
\hline 3 & Setting 03 & 5 & 10 & 150 & $5-10-150$ & 17 & Setting 17 & 10 & 30 & 100 & $10-30-100$ \\
\hline 4 & Setting 04 & 5 & 20 & 50 & $5-20-50$ & 18 & Setting 18 & 10 & 30 & 150 & $10-30-150$ \\
\hline 5 & Setting 05 & 5 & 20 & 100 & $5-20-100$ & 19 & Setting 19 & 15 & 10 & 50 & $15-10-50$ \\
\hline 6 & Setting 06 & 5 & 20 & 150 & $5-20-150$ & 20 & Setting 20 & 15 & 10 & 100 & $15-10-100$ \\
\hline 7 & Setting 07 & 5 & 30 & 50 & $5-30-50$ & 21 & Setting 21 & 15 & 10 & 150 & $15-10-150$ \\
\hline 8 & Setting 08 & 5 & 30 & 100 & $5-30-100$ & 22 & Setting 22 & 15 & 20 & 50 & $15-20-50$ \\
\hline 9 & Setting 09 & 5 & 30 & 150 & $5-30-150$ & 23 & Setting 23 & 15 & 20 & 100 & $15-20-100$ \\
\hline 10 & Setting 10 & 10 & 10 & 50 & $10-10-50$ & 24 & Setting 24 & 15 & 20 & 150 & $15-20-150$ \\
\hline 11 & Setting 11 & 10 & 10 & 100 & $10-10-100$ & 25 & Setting 25 & 15 & 30 & 50 & $15-30-50$ \\
\hline 12 & Setting 12 & 10 & 10 & 150 & $10-10-150$ & 26 & Setting 26 & 15 & 30 & 100 & $15-30-100$ \\
\hline 13 & Setting 13 & 10 & 20 & 50 & $10-20-50$ & 27 & Setting 27 & 15 & 30 & 150 & $15-30-150$ \\
\hline 14 & Setting 14 & 10 & 20 & 100 & $10-20-100$ & & & & & & \\
\hline
\end{tabular}

Remarks: hs : Spatial radius (pixel), hr : Range radius/spectral value (DN) and M : Minimum region size (pixel)

Spatial radius is a parameter that has a function to control the distance, measured by a number of pixels. The spatial radius will group a number of pixels into one segment or one object, whereas the range radius is a segmentation parameter that corresponds to the spectral value of each pixel. The range radius refers to spectral variability (distance in n-dimensional spatial space) to group a number of pixels into a single segment. Furthermore, it is also defined that the minimum region size (M) is a parameter related to the minimum size of the number of pixels that form a single object. Objects that have the number of pixels below the parameter value will be combined with the nearest object. After the parameter values are determined, the segmentation process is performed on all four research clusters. At the end process, since the segmentation was processed on the raster-formatted data, an output of the segmentation would also raster format. Finally, it is needed to convert raster data into a vector format.

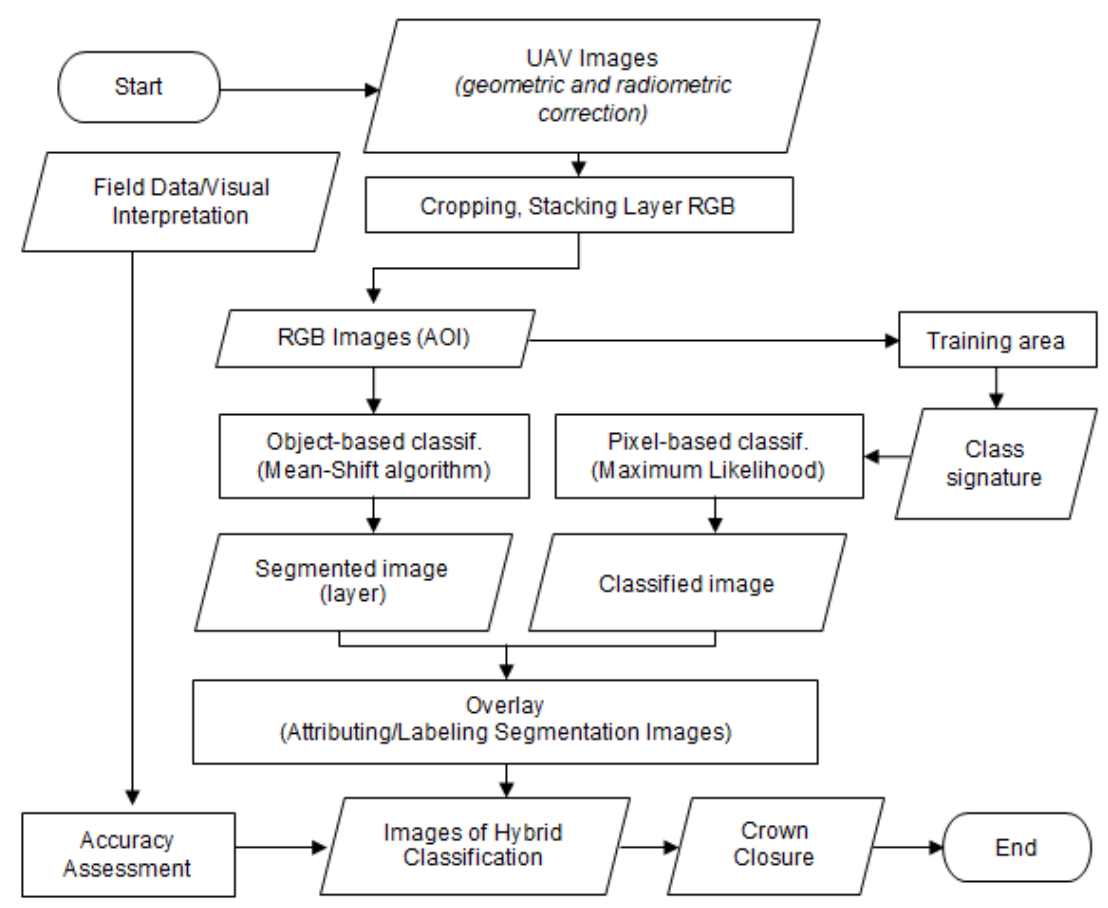




\subsubsection{Classification}

Figure 2. Flow diagram of the study process

In this study, the author applied the hybrid between the object-based (segmentation, OBIA) and pixel-based maximum likelihood classifier (MLC). The results of segmentation classification results of segmentation run using Orfeo Toolbox/Monteverdi was then incorporated with the results of supervised classification run using ERDAS imagine. During the classification using MLC, several classes were defined, namely nypa canopy, mangrove canopy, bare land, gap, and water body. The results of supervised classification have then used an attribute of each polygon obtained during segmentation. The classification step outlined in this study is depicted in Figure 2.

\subsubsection{Accuracy Assessment}

One of the important issues in determining the optimal segmentation is in the accuracy assessment. Although there are some method to assess the performance of segmentation such as fragmentation index [28], the area fit index [29] and there is also another method to evaluate the segmentation result using area, perimeter and shape index (SI) [30]. This study used a comparison between the segmentation results with reference area.

To identify the most accurate segmentation parameter for assessing the nypa crown closure and gaps, the conventional confusion matrix analysis was performed. The data reference used for expressing the actual crown closure and gaps derived is the data derived from visual interpretation and ground observation. The comparison between the automated classification (OBIA and MLC) was then used to calculate the overall accuracy (OA) and kappa accuracy as the follows [31].

$$
\begin{aligned}
& \mathrm{OA}=\left[\frac{\sum_{\mathrm{i}=1}^{\mathrm{r}} \mathrm{X}_{\mathrm{ii}}}{\mathrm{N}} \times 100 \%\right] \\
& \mathrm{K}=\frac{\mathrm{N} \sum_{\mathrm{i}=1}^{\mathrm{r}} \mathrm{X}_{\mathrm{ii}} \sum_{\mathrm{i}=1}^{\mathrm{r}} \mathrm{X}_{\mathrm{i}+} \mathrm{X}_{+\mathrm{i}}}{\mathrm{N}^{2}-\sum_{\mathrm{i}}^{\mathrm{X}} \mathrm{X}_{\mathrm{i}+} \mathrm{X}_{+\mathrm{i}}} \times 100 \%
\end{aligned}
$$

Remarks:

OA : Overall accuracy $(\%)$

$\mathrm{K} \quad$ : Kappa accuracy $(\%)$

$\mathrm{X}_{\mathrm{ii}} \quad$ : Coincided value (number of pixel)

$\mathrm{N} \quad$ : Total pixel

$\mathrm{K} \quad$ : Kappa accuracy $(\%)$

$\mathrm{X}_{\mathrm{i}+} \quad$ : The sum of column $\mathrm{j}$

$\mathrm{X}_{+\mathrm{i}} \quad$ : The sum of row $\mathrm{i}$

\subsubsection{Crown Closure}

The results of the accuracy assessment for all combinations of the parameter setting were used to identify the optimal segmentation parameters. The best combination of segmentation parameter was then used to calculate the value of crown closure $(\mathrm{Cc})$ of nypa in each cluster. Prior to any further process, the cluster was simulated into several plot forms according to the shape and size of the field plot. Selection of the most optimal plot size simulation was done by considering the coefficient of covariance (CV) value of the biomass, volume and nypa density variation. The percentage of crown closure is the ratio between total crown coverage $\left(\mathrm{m}^{2}\right)$ and plot size $\left(\mathrm{m}^{2}\right)$.

\section{RESULTS AND ANALYSIS}

The selection of the best segmentation parameters is done by evaluating the average value of overall accuracy (OA) and kappa accuracy (KA) for all four clusters. Recapitulation of accuracy values of OA and KA are summarized in Figure 3. The accuracy value was derived by comparing the segmentation and visual interpretation as well as field observation as reference data.

Of the 27 combinations of the segmentation parameter examined, we found that the relatively high accuracy in predicting the crown closure of nypa were provided by the setting-10 (10-10-50), setting-01 (510-50), setting-04 (5-20-50) and setting-19 (15-10-50) having overall accuracy between $76.5 \%$ and $76.6 \%$ and kappa accuracy between 55.6 and $55.7 \%$ (Figure 3). The classification accuracy obtained by applying the combination of mean-shift algorithm and pixel-based maximum likelihood classifier is slightly lower than the accuracy of the combination mean-shift algorithm and support vector machine (SVM) classification 
examined by [25]. This is mis due to the size, shape and brightness value of the nypa vegetation more complicated than size, shape and brightness value of the building objects.

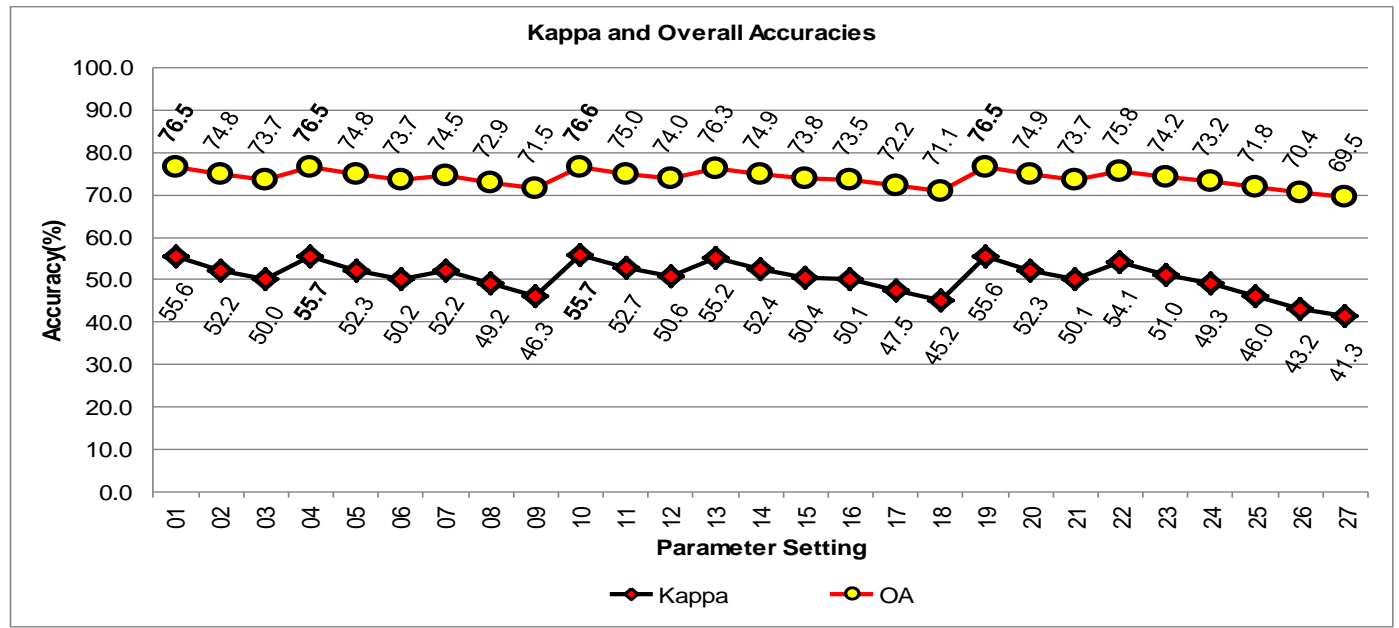

Figure 3. Overall and Kappa Accuracy for all combination of segmentation parameter

From these accuracy values, it is noted that the variation in the values of spatial radius and range radius does not provide a significant difference of accuracy (Figure 4). No significant difference in accuracy was obtained when the spatial radius was increased or decreased. Of all setting, it seems that the most accurate spatial radius parameter for predicting the crown closure is 10 pixels. When the spatial radius is changed to 15 then the accuracy decreased. From the range radius point of view, the increase of range radius from 10 to 20 causing the decline in OA from $76.6 \%$ to $76.3 \%$, very tiny change (see setting-10 (10-10-50) and setting-13 (10-20-50)) (Figure 4b). The range radius differed significantly when it raised from 20 to 30 pixels (Figure 4b), causing a decrease of overall accuracy $2.8 \%$ and kappa accuracy of about $5.1 \%$.

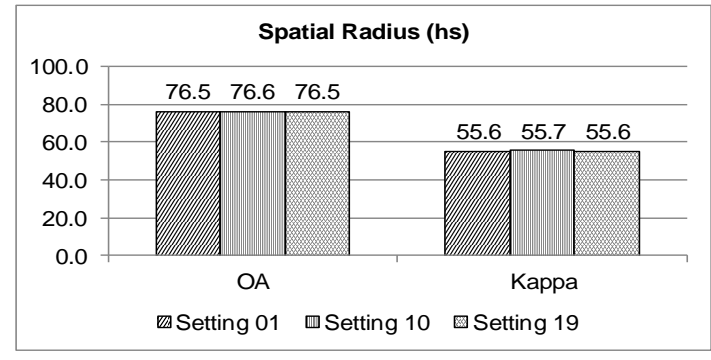

a)

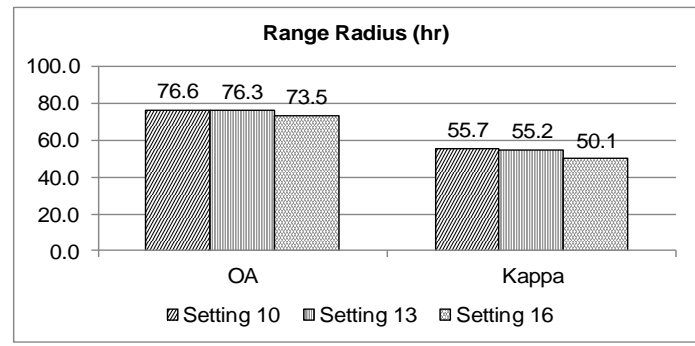

b)

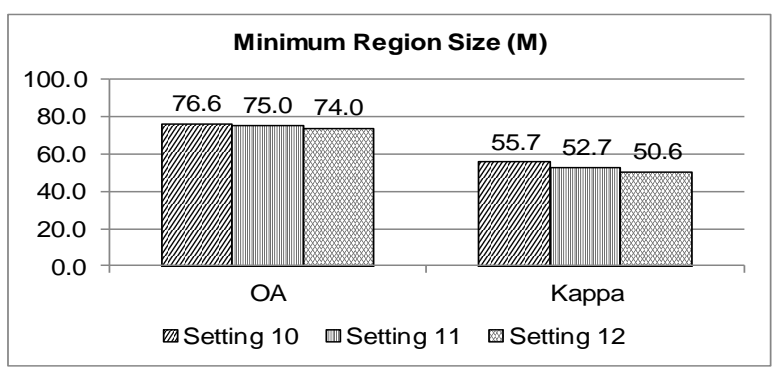

c)

Figure 4. Overall and Kappa accuracy for all parameter

The third parameter we observed was the minimum region size (M). This $\mathrm{M}$ parameter determines the number of pixels that may compose a single segment (object). We set up the M size on the basis of the 
individual diameter of nypa tree, that ranging from $0.5 \mathrm{~m}^{2} \sim 1.5 \mathrm{~m}^{2}$. These $\mathrm{M}$ values are from 50 to 150 pixels. The study found that the high accuracy settings are obtained from the value $\mathrm{M}$ of 50 pixels. The $\mathrm{M}$ having size more than 50 pixels reduce the overall accuracy. The minimum region size differed significantly when it raised to 100 pixels (Figure 4c), and causing a decrease of overall accuracy $2.6 \%$ and kappa accuracy $5.1 \%$.

Among the three segmentation parameters evaluated, it is shown that the $\mathrm{M}$ is the most affecting parameters, larger than the spatial radius and range radius. This is in line with the study carried out by [27], expressing that spatial radius was less sensitive than the other segmentation parameter. The $\mathrm{M}$ is expressing the nypa size (crown coverage). The radius range which expresses the range of spectral is less sensitive in distinguishing the nypa leaves and gap. Thus it causes less significant in segmentation processes of the crown closure analysis of the nypa.

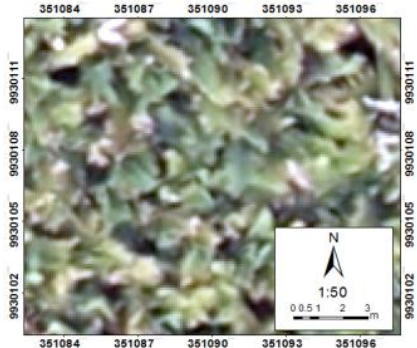

(1)

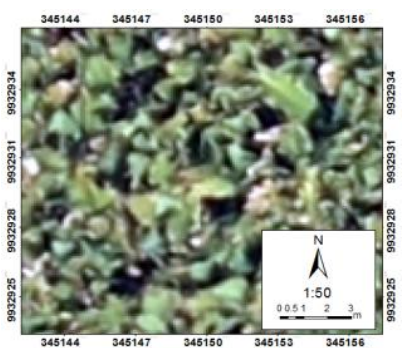

(1)

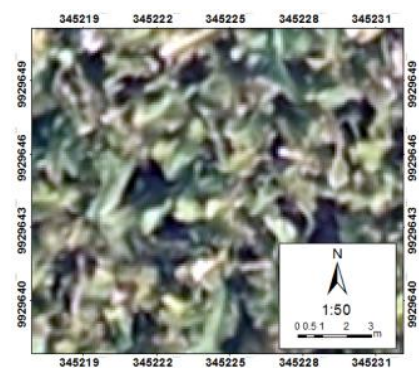

(1)

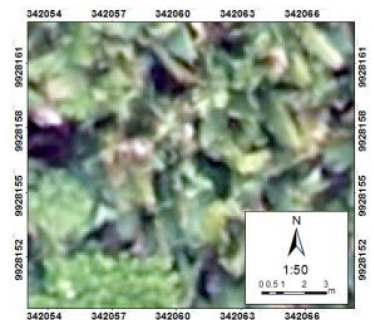

(1)

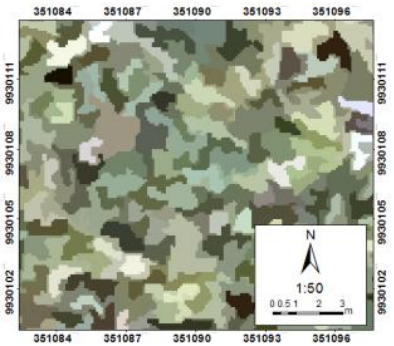

(2)

a) Cluster 1

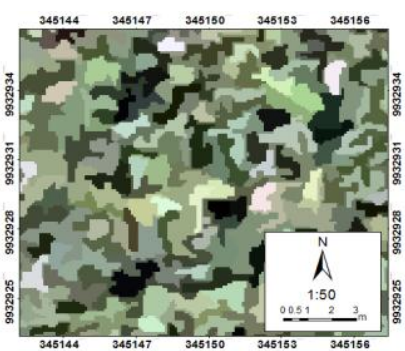

(2)

b) Cluster 2

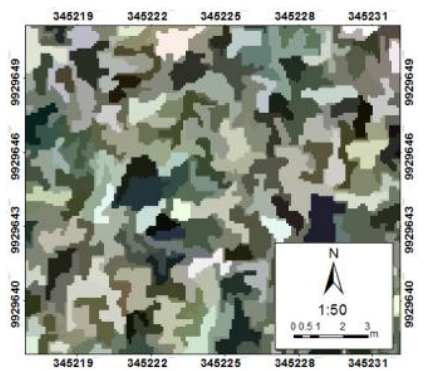

(2)

c) Cluster 3

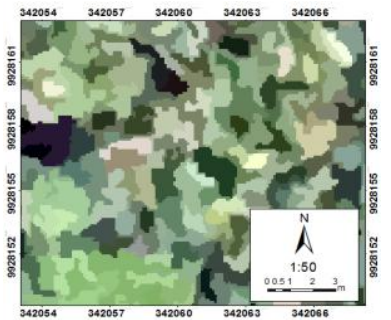

(2)

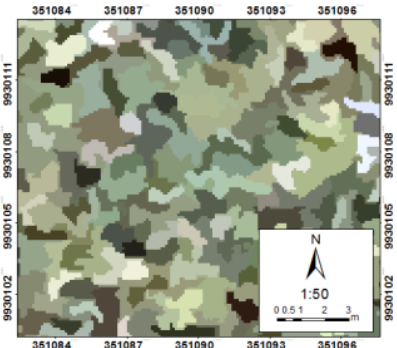

(3)

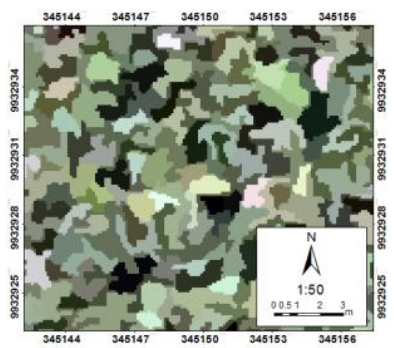

(3)

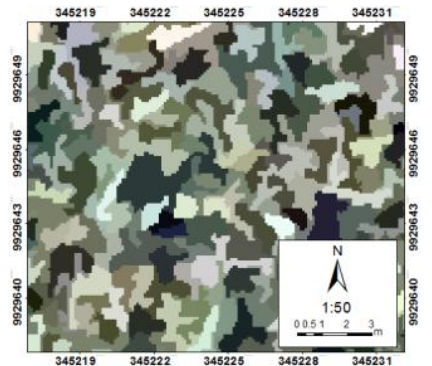

(3)

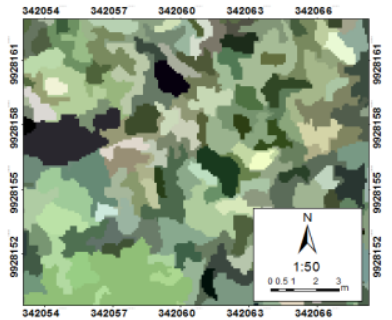

(3)

d) Cluster 4 
Figure 5. Comparison between sample of original image of the UAV (left column : 1) with segmentation results using setting-10 (middle column : 2) and the setting-04 (right column : 3) at cluster 1 (a) cluster 4 (d).

To increase the accuracy of crown closure delineation, the authors also applied a pixel-based classifier that relies on its spectral signature. The segmentation result was then combined with the classification result obtained from the supervised classification. This is in line with the study of [20] for identification of benthic habitat. However, his finding provided a very low overall accuracy of only $27.7 \%$. His study noted that low accuracy may be due to the gap from segmentation process when integrating phototransect and cluster. Besides, the low accuracy may be due to the sample location that does not match with the object in the map.

The examination on the use of a pixel-based method to classify crown closure and the gap was also performed. However, the study results show that its ability to identify the object is still low. One of its drawbacks is in the labeling of objects, which is only based on the brightness value or color of the object, without considering the spatial aspects such as location, size, shape, texture, etc. The success or failure of pixel-based classification is solely determined by its brightness value. Thus, the quality of the object classification results depends on the quality of pixel-based qualification results. The difficulty in determining the spectral separation of a class also becomes a challenge in pixel-based classification particularly in using the high-resolution data. The low accuracy of using spectral range (radiometric) might be due to the image quality (blurring/image motion and low spectral resolution) [32, 33]. The image blurring due to the high image motion affect the ability of UAV image in identifying the object of interest [32, 33]. The presence of noise also reduces the accuracy of segmentation. In the very high-resolution imagery, it is quite common that the small size of gaps among trees, branches, twigs, and leaves causing "salt and pepper" noise. The other source of noise may come from the misregistration and geometric correction during pre-processing stage. Based on the best-selected parameter segmentation setting-10, the crown closure of nypa within the sampling plot are ranging from $38.4 \%$ to $61.6 \%$.

\section{CONCLUSION}

From the foregoing results and discussions, this study concludes that the most optimal segmentation parameters in measuring the crown closure of nypa and gap is provided by the setting-10, which has 10 for spatial radius, 10 for range radius and 50 for minimum region size. The accuracy of this segmentation parameter combination provides approximately $76.6 \%$ of overall accuracy and $55.7 \%$ for kappa accuracy. This study also concluded that variation of minimum region size $(\mathrm{M})$ contribute a significant variation in accuracy assessment, greater than another parameter spatial radius (hs) and range radius (hr). The classification technique by combining of pixel-based and object-based has given a promising result in delineating a very small feature within the nypa vegetation.

\section{REFERENCES}

[1] Duke NC. Mangrove Floristics and Biogeography. In: Robertson AI, Alongi DM. Editors. Tropical Mangrove Ecosystems. Washington DC: American Geophysical Union.1992. 63-100.

[2] Heriyanto NM, Subiandono E, Karlina E. Potensi dan sebaran Nipah (Nyfa fructicans (Thunb.) Wurmb) Sebagai Sumberdaya Pangan. Jurnal Pendidikan Hutan dan Konservasi Alam. 2011; 8(4): 327-335.

[3] Tamunaidu S, Matsui N, Okimori Y, Saka S. Nipa (Nypa fruticans) sap as a potential feedstock for ethanol production. Journal Biomass and Bioenergy. 2013; 52: 96-102.

[4] Everaerts J. The Use Of Unmanned Aerial Vehicles (UAVS) for Remote Sensing And Mapping. The International Archives of The Photogrammetry, Remote Sensing and Spatial Information Sciences. 2008; 38: 1187-1192.

[5] Getzin S, Nuske RS, Wiegand K. Using Unmanned Aerial Vehicle (UAV) to Quantify Spatial Gap Patterns In Forests. Remote Sens. 2014; 6(8): 6988-7004.

[6] Wallace L, Lucieer A, Watson C. Assesing the Feasibility of UAV-based LiDAR for High Resolution Forest Change Detection. The 12th Congress of the International Society for Photogrammetry and Remote Sensing. Melbourne. 2012; 39: 499-504.

[7] Wallace L, Lucieer A, Turner D, Watson C. Error Assessment And Mitigation For Hyper-Temporal UAV-Borne Lidar Surveys Of Forest Inventory. The 11th International Conference on LiDAR Applications for Assessing Forest Ecosystems. Hobart. 2012; 1-13.

[8] Dandois JP, Ellis EC. High Spatial Resolution Three-Dimensional Mapping Of Vegetation Spectral Dynamics Using Computer Vision. Journal Remote Sensing of Environment. 2013; 136: 259-276.

[9] Jaya INS, Cahyono AB. Kajian Teknis Pemanfaatan Potret Udara Non-Metrik Format Kecil Pada Bidang Kehutanan. Jurnal Manajemen Hutan Tropika. 2001; 7(1): 55-64.

[10] Jaya INS, Kleinn C, Melati D, Fehrmann L, Pérez-Cruzado C, Septyawardani E, Dhani FAR, Wachjuni S. Utilizing Multi-Source Data For Sustainable Forest Managements In Indonesia. Bridging The Gap Between Information 
Needs And Forest Inventory Capacity. Proceedings of the $5^{\text {th }}$ International DAAD Workshop. Durban dan Pietermaritzburg. 2015: 163-181.

[11] Kusnadi, Jaya INS, Puspaningsih N, Basuki M, Hakim L. Model Penduga Kualitas Tempat Tumbuh Jati (Tectona grandis) Menggunakan Citra Resolusi Sangat Tinggi Pesawat Tidak Berawak Di KPH Nganjuk. Jurnal Penelitian Kehutanan Wallace. 2016; 5(2): 185-194.

[12] Blaschke T. Object Based Image Analysis for Remote Sensing. ISPRS Journal of Photogrammetry and Remote Sensing. 2010; 65(1): 2-16.

[13] Pal NR, Pal NK. A Review on Image Segmentation Techniques. Pattern Recognition. 1993; 26(9): 1277-1294.

[14] Duro DC, Franklin SE, Dube MG. A Comparison of Pixel-Based and Object-Based Image Analysis With Selected Machine Learning Algorithms for The Classification of Agricultural Landscapes Using Spot HRG Imagery. 2012; 118: 259-272.

[15] Sari NM, Kushardono D. Object Segmentation on UAV Photo Data to Support the Provision of Rural Area Spatial Information. Forum Geografi. 2015; 29(1): 49-58.

[16] Wahidin N, Siregar VP, Nababan B, Jaya I, Wouthuyzen S. Object-based Image Analysis for Coral Reef Benthic Habitat Mapping with Several Classification Algorithms. Procedia Environmental Sciences. 2015; 24: 222-227.

[17] Conchedda G, Durieux L, Mayaux P. An Object-based Method for Mapping and Change Analysis in Mangrove Ecosystem. International Journal of Remote Sensing. 2008; 63(5): 578-589.

[18] Chehata N, Orny C, Boukir S, Guyon D, Wigneron JP. Object-based Change Detection in Wind Storm-Damaged Forest Using High Resolution Multispectral Images. International Journal of Remote Sensing. 2014; 35(13): 47584777.

[19] Lackner M, Conway TM. Determining Land-use Information from Land Cover Through an Object-oriented Classification of IKONOS Imagery. Canadian Journal of Remote Sensing. 2008; 34(2): 77-92.

[20] Wicaksono P, Farda NM. Aplikasi Algoritma Klasifikasi Mean Shift untuk Pemetaan Habitat Bentik Studi Kasus Kepulauan Karimunjawa. Prosiding Pertemuan Ilmiah Tahunan XX. Bogor. 2015: 663-672.

[21] Ballari D, Orellana D, Acosta E, Espinoza A, Morocho V. UAV Monitoring for Enviromental Management in Galapagos Island. The International Archives of the Photogrammetry, Remote Sensing and Spatial Information Sciences. ISPRS Congress XXIII. Prague. 2016: Vol XLI-B1. 1105-1111.

[22] Lin H. Method of Image Segmentation on High-Resolution Image and Classification for Land Covers. Fourth International Conference on Natural Computation. Jinan. 2008: 563-566.

[23] Aiazzi B, Alparone L, Baronti S, Garzelli A, Zoppetti C. Nonparametric Change Detection In Multitemporal SAR Images Based On Mean-Shift Clustering. IEEE Transactions on Geoscience and Remote Sensing. 2013; 51(4): 2022-2031.

[24] Ting Y, Mingxing G, Yanming W. Ultrasound Image Segmentation based on the Mean-Shift and Graph Cuts Theory. TELKOMNIKA. 2013; 11(10): 5600-5608.

[25] Benarchid O, Raissouni N. Support Vector Machine for Object Based Building Extraction in Suburban Area Using Very High Resolution Satellite Images, a Case Study: Tetuan, Morocco. Indonesian Journal of Artificial Intelligence. 2013; 2(1): 43-50.

[26] Fukunaga K, Hostetler LD. The Estimation of the Gradient of a Density Function, with Application in Pattern Recognition. IEEE Transactions on Information Theory. 1975; 21(1): 32-40.

[27] Comaniciu D, Meer P. Mean Shift: A Robust Approach Toward Feature Space Analysis. IEEE Transactions of Pattern Analysis and Machine Intelligence. 2002; 24(5): 603-619.

[28] Strasters KC, Gerbrands JJ. Three-dimensional Image Segmentaion Using A Split, Merge and Group Approach. Pattern Recognition Letter. 1991; 12(5): 307-325.

[29] Lucieer A. Uncertainties in Segmentation and Their Visualisation. PhD Thesis. Utrecht: Utrecht University; 2004.

[30] Neubert M, Herold H, Meinel G. Assessing Image Segmentation Quality - Concepts, Methods and Application. In: Blaschke T, Hay G, Lang S. Editors. Object-Based Image Analysis - Spatial Concepts For Knowledge-Driven Remote Sensing Applications. Lecture Notes in Geoinformation \& Cartography (LNG\&C). Berlin: Springer; 2008: 769-784.

[31] Jaya INS. Analisis Citra Digital, Perspektif Penginderaan Jauh untuk Pengelolaan Sumberdaya Alam. Bogor: Institut Pertanian Bogor. 2015: 185-232.

[32] Wahyuni S, Jaya INS, Puspaningsih N. Model for Estimating Above Ground Biomass of Reclamation Forest Using Unmanned Aerial Vehicles. Indonesian Journal of Electrical Engineering and Computer Science. 2016; 4(3): 586593.

[33] Zheng L, Zhang J, Wang Q. Mean-Shift Based Color Segmentation of Images Containing Green Vegetation. Computers and Electronics in Agriculture. 2008; 65(1): 93-98. 